\title{
Repeated survey on changes in musculoskeletal complaints relative to age and work demands
}

\author{
Bart C H de Zwart, Jake P J Broersen, Monique H W Frings-Dresen, Frank J H van Dijk
}

\begin{abstract}
Objectives-To examine changes in musculoskeletal complaints over four years in groups of employees relative to age and work demands.

Methods-Repeated questionnaire data of male employees in heavy physical work (exposed group, $n=7324$ ) and mental work (control group, $n=4686$ ), stratified for age (20-9, 30-9, 40-9, 50-9), were analysed. For each employee, data on the occurrence of musculoskeletal complaints from two surveys with a mean interval of around four years were available. Changes in prevalences over the follow up interval were analysed. Proportions of new, recovered, and chronic cases as well as those free of complaints at both surveys were studied.

Results-For most complaints, there were significantly greater increases in prevalences in the exposed group compared with the control group over the follow up interval particularly within the group aged 40-9 for back, neck, and several sites of the upper and lower limbs. The 20-9 year age group also had significantly greater changes for several musculoskeletal complaints. Within the oldest age group (50-9) exposure to heavy physical work demands only affected changes in prevalences of neck and upper arm complaints. After four years in the cohort free of complaints at the start of the follow up the group aged 40-9 had the highest prevalence of complaints of the back, neck, and the upper and lower limbs.

Conclusions-Middle aged and younger employees develop musculoskeletal complaints as a result of exposure to heavy physical work. In the oldest age group health related selection seems to mask the occupational health risks under study. To prevent the expected increase in musculoskeletal disorders and related work disability in our aging workforce, preventive measures should be taken at all stages of a working life.
\end{abstract}

(Occup Environ Med 1997;54:793-799)

Dr Bart $\mathrm{CH}$ de Zwart,

Coronel Institute for

Occupational and

Environmental Health,

Academic Medical Center,

University of Amsterdam,

PO Box 22700, $1100 \mathrm{DE}$

Amsterdam, The

Netherlands. Tel: 003120

566 2799/5325; Fax: 0031

206977161 ;

Email·b.c.dezwart@amc.uva.n

Accepted 8 August 1997 of musculoskeletal disorders with advancing age among employees in physically demanding occupations. ${ }^{1-4}$ Most of these surveys were lim-

Keywords: musculoskeletal complaints; aging; physical

Over the past years, several epidemiological Over the past years, several epidemiological ited to cross sectional data, offering weak evidence for causality due to uncertainty over the time of exposure and bias by a health related selection of employees.

Longitudinal studies are considered to be more appropriate for studying the combined effects of aging and exposure to physical work demands on the development of musculoskeletal complaints, even though these studies also have their specific problems. ${ }^{5}$ Published data on these kinds of studies are scarce. In a four year follow up study of Tuomi et $a l,{ }^{6}$ an increase from $36 \%$ to $50 \%$ in prevalence of musculoskeletal diseases was reported among male employees in physically demanding jobs compared with a change from $25 \%$ to $38 \%$ among those in mentally demanding jobs. These findings, however, were based on only one particular age group, employees aged 45 or older.

It might be suggested that several age related factors are responsible for an increased risk of developing musculoskeletal complaints with advancing age for employees in physically demanding occupations: (a) biological changes with age-for example, degenerative changes of the intervertebral $\operatorname{discs}^{7} ;(b)$ the age related increase in number of years of expcsure to harmful work demands; $;^{28}$ and (c) a gradual change in the balance between physical workload and physical work capacity as a result of a declining physical work capacity with age not compensated for by adaptations in tasks and working conditions. ${ }^{910}$ With this in mind, differences in the development of musculoskeletal complaints between age groups may be expected over a follow up interval of several years.

The aim of this study was to examine changes in musculoskeletal complaints over about four years among groups of employees relative to age and work demands.

\section{Materials and methods}

QUESTIONNAIRE

Regional occupational health services in The Netherlands take care of the health and wellbeing of the employees of affiliated companies. Roughly every four years, these employees are invited by their regional occupational health services to participate in a periodic occupational health survey. The surveys are normally carried out company wide on a voluntary basis (participation rate $75 \%-80 \%{ }^{11}$ ). All participating employees of a company are examined within a survey period of a few weeks. Part of the survey is a standardised questionnaire which has to be completed by the employees 
Table 1 Distribution of the study population over various occupational classes stratified for types of work demands

\begin{tabular}{|c|c|}
\hline & $n(\%)$ \\
\hline \multicolumn{2}{|l|}{ Mental. } \\
\hline Physical scientists & $171(4)$ \\
\hline Architects, engineers & $842(18)$ \\
\hline Statisticians, system analysts & $93(2)$ \\
\hline Authors, journalists & $74(2)$ \\
\hline Professional, technical workers & $165(4)$ \\
\hline Managers & $652(14)$ \\
\hline Government executive officials & $211(5)$ \\
\hline Book-keepers, cashiers & $312(7)$ \\
\hline Transport and communications supervisors & $90(2)$ \\
\hline Clerical supervisors & $962(21)$ \\
\hline Sales supervisors and buyers & $117(2)$ \\
\hline $\begin{array}{l}\text { Technical salesmen, commercial travellers, and manufacturers' } \\
\text { agents }\end{array}$ & $162(3)$ \\
\hline $\begin{array}{l}\text { Insurance, real estate, securities and business services salesmen, and } \\
\text { auctioneers }\end{array}$ & $50(1)$ \\
\hline Protective service workers & $67(1)$ \\
\hline Production supervisors and general foremen & $489(10)$ \\
\hline Others ( 16 classes $<50$ workers) & $229(5)$ \\
\hline Total & $4686(100)$ \\
\hline \multicolumn{2}{|l|}{ Heavy physical } \\
\hline Agricultural and animal husbandry workers & $339(5)$ \\
\hline Metal processors & $374(5)$ \\
\hline Wood preparation workers and paper makers & $236(3)$ \\
\hline Chemical processors & $94(1)$ \\
\hline Spinners, weavers, knitters, and dyers & $71(1)$ \\
\hline Food and beverage processors & $317(4)$ \\
\hline Tobacco preparers and product makers & $115(2)$ \\
\hline Cabinet makers and woodworkers & $276(4)$ \\
\hline Toolmaker and machine tool operators & $585(8)$ \\
\hline $\begin{array}{l}\text { Machinery fitters, machine assemblers, and precision instrument } \\
\text { makers }\end{array}$ & $909(12)$ \\
\hline Electrical fitters and related electrical and electronics workers & 327 (4) \\
\hline $\begin{array}{l}\text { Plumbers, welders, sheet metal and structural metal preparers, and } \\
\text { erectors }\end{array}$ & $298(4)$ \\
\hline Rubber and plastic products makers & $72(1)$ \\
\hline Paper and paperboard product makers & $371(5)$ \\
\hline Printers and related workers & $234(3)$ \\
\hline Painters & $278(4)$ \\
\hline Production workers & $111(2)$ \\
\hline Bricklayers, carpenters, and other construction workers & $1201(16)$ \\
\hline $\begin{array}{l}\text { Material handling and related equipment operator, dockers, and } \\
\text { freight handlers }\end{array}$ & $704(10)$ \\
\hline Labourers (physical) not elsewhere classified & $323(4)$ \\
\hline Others $(8$ classes $<50$ workers $)$ & $91(1)$ \\
\hline Total & $7324(100)$ \\
\hline
\end{tabular}

themselves. The questionnaire comprises 55 items about work and working conditions and 117 items about health, all to be answered with yes or no only. For this paper, the data from 19 questions on musculoskeletal complaints in various areas of the body were selected from the survey questionnaire (table 3 ). The questions were generally phrased; "Do you regularly have pain or stiffness in the - ${ }^{11}$

\section{STUDY POPULATION}

Between 1982 and 1993, 44486 employees participated in a survey once or more, some even up to four times. All surveys were carried out by one regional occupational health service in the eastern part of The Netherlands (Doetinchem). Employees worked in a wide range

Table 2 Number of male employees studied, mean (SD) age, and follow up time between repeated surveys, stratified for age group and types of work demands (age group refers to age at T1)

\begin{tabular}{llllll}
\hline \multicolumn{5}{l}{ Age group (y) } \\
\cline { 2 - 6 } Types of work demands & $20-9$ & $30-9$ & $40-9$ & $50-9$ & Total \\
\hline Mental: & & & & & \\
$\quad$ n & 772 & 1814 & 1365 & 735 & 4686 \\
Age (mean (SD) y) & $25.9(2.3)$ & $34.9(2.7)$ & $44.2(3.0)$ & $53.0(2.4)$ & $39.0(9.0)$ \\
$\quad$ Follow up (mean (SD) y) & $4.0(0.3)$ & $3.9(0.5)$ & $3.8(0.6)$ & $3.6(0.5)$ & $3.9(0.5)$ \\
Heavy physical: & & & & & \\
$\quad$ n & 1721 & 2553 & 1934 & 1116 & 7324 \\
Age (mean (SD) y) & $25.1(2.6)$ & $34.7(2.6)$ & $44.1(3.0)$ & $52.7(2.2)$ & $37.7(9.6)$ \\
Follow up (mean (SD) y) & $4.0(0.4)$ & $4.1(0.7)$ & $3.9(0.7)$ & $3.5(0.5)$ & $3.9(0.6)$ \\
\hline
\end{tabular}

(several hundreds) of occupations. For this study, a selection was made of all male employees who participated at least twice in a survey during this period, with an interval between the first and second survey varying between 2.5 and 5.5 years (mean 3.9 years). Only subjects with results at both surveys were used, leading to a fixed cohort. Only data from men were selected for further analysis as there were too few women.

Employees aged 20-59 at the first survey were selected and four equal age strata were constructed according to age at that time (20-9, 30-9, 40-9, 50-9). Stratification was made for work demands based on the employee's job title according to the classification described by De Zwart et al. ${ }^{12}$ Four categories of work demands are distinguished in this classification; mentally demanding work; mixed mentally and physically demanding work; light physically demanding work; and heavy physically demanding work. For our study, only subjects within the two most contrasting categories were selected-that is, employees in the categories of mentally demanding work and heavy physically demanding work. In this paper these categories will be referred to as mental and heavy physical. Data from subjects in the two other categories were excluded from the analyses because of the few employees, especially in the oldest age group.

The category mental work-the control population-is characterised by sedentary occupations. Jobs in the category heavy physical work are characterised by tasks such as lifting heavy objects, handling heavy tools, and often stooping in combination with standing or walking. Employees who changed their work tasks between the first and second survey, as a consequence of a change in job, were excluded from analyses. Tables 1 and 2 present several characteristics of the study population.

\section{DATA ANALYSIS}

Within each stratified group, prevalences of the various musculoskeletal complaints were computed on the basis of questionnaire data for each survey separately. Also, changes in prevalences of complaints between the two surveys were calculated at group level. Within each age group these changes in prevalences in the group in heavy physical work (exposed) versus those in mental work (control) were tested. As effect measure $Y$-the change in prevalence between the two surveys-in the exposed group minus the change in the control group was used. The applied test statistic is presented in the appendix. Differences were considered significant when the $P$ value was $<0.05$.

\section{Results}

The figure and table 3 show the changes in prevalences of shoulder complaints over four years. Within all age groups the prevalences of shoulder and other reported musculoskeletal complaints at both surveys were substantially greater in the category of heavy physical work when compared with the control category of mental work (table 3 ). When comparing prevalences at the first survey between the four age 


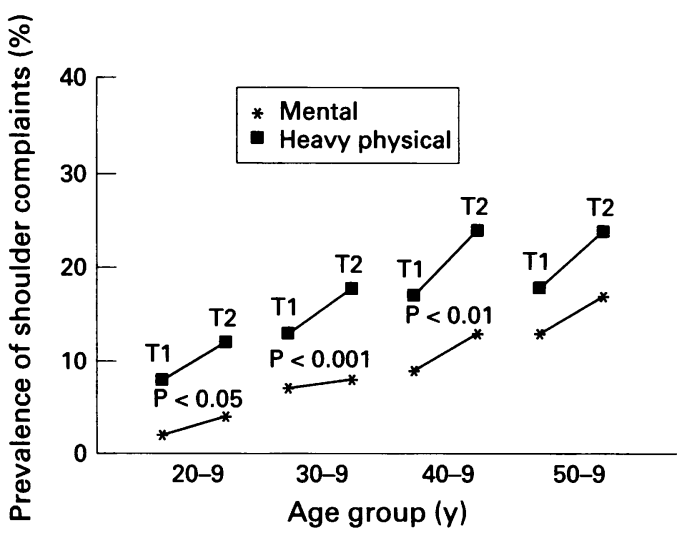

Figure 1 Changes in prevalences of complaints of the shoulder between the first (T1) and the second (T2) survey for male employees, stratified for age group and work demands (total $n=12010$ ). Statistics compared the difference in change in prevalence between the two surveys in heavy physical work versus mental work. Age group refers to age at the first survey.

groups, a common finding was that they increased from the youngest age group to the group aged 40-9. For most complaints this increase was followed by a flattening or even decreasing pattern between the two oldest age groups (40-9 and 50-9). This was particularly obvious in the heavy physically exposed group.

When focusing on changes in prevalences of shoulder complaints over four years (prevalence at the second minus prevalence at the first survey), significantly greater increases between the first and second surveys were found for the physically exposed category than for the control population in the age groups 20-9, 30-9, and 40-9 ( $P<0.05, P<0.001$, and $\mathrm{P}<0.01$ respectively, figure). No significant differences were reported for the oldest age group (50-9). For most complaints, greater increases were reported among employees in heavy physically demanding work compared with those in mentally demanding work (table 3 ). Many significant differences were found in the age group 40-9 years, and several in the groups aged $20-9$ and $30-9$. In the oldest age group, significant differences were only present for complaints of the neck and upper arm $(\mathrm{P}<0.05)$. For the upper limbs, complaints of the shoulder were found to be most common, showing relatively large changes in prevalences within all age groups. For the lower limbs, comparable high prevalences were found for complaints of the knee and hip.

The net changes in prevalences over several years within a fixed cohort of employees with and without complaints at the start of the follow up (table 3), are entirely based on the difference between the number of employees developing complaints over the interval (new cases) versus those recovering from complaints (recovered cases). Table 4 shows the distribution of these new and recovered cases with those reporting complaints at both surveys (chronic cases) and those free of complaints at both surveys.

The number of chronic cases increased with age in both types of work (table 4). For complaints of the back and upper and lower limbs, significantly greater frequencies of chronic cases were present among employees in heavy physical jobs than in those who did mental work within all age groups. The proportion of cases who recovered in the youngest age group was high when related to the number of cases with complaints at the first survey (sum of the number of chronic cases plus recovered cases). For all age groups in both types of work the number of recovered cases never exceeded the number of new cases, resulting in a net increase in prevalences over the four years of follow up (table 3). For all four complaints reported in table 4 the largest difference between the new and recovered cases was found for the age group 40-9 in heavy physically demanding work.

Table 4 also shows prevalences at the second survey of complaints of the back, neck, and the upper and lower limbs among a selected cohort of employees free from complaints at the first survey. As all cases at the second survey represent new events, this prevalence may be considered as a rough approximation of the cumulative incidence over the four year interval. Significantly greater prevalences of all new complaints reported in table 4 were found in the age groups $20-9,30-9$, and 40-9 in heavy physical work compared with the control group. For the oldest age group (50-9) significant differences were absent. With the exception of complaints of the neck, an increasing trend in prevalence was found with age up to the age group 40-9 in heavy physical work. An already high prevalence of new back complaints of $18 \%$ was found in the youngest age group in heavy physical work relative to the other age groups. For all complaints in this type of work, prevalences remained at a stable level or declined slightly between the two oldest age groups. This decrease was not found in the group with mental work.

\section{Discussion}

In the present study, changes in musculoskeletal complaints over about four years among employees in several age groups were examined relative to types of work. For most of the complaints exposure to heavy physically demanding work affected the rate of change of these complaints in the age group 40-9 years. A similar effect for fewer complaints was also present in the two youngest groups, 20-9 and 30-9.

\section{SUBJECTS}

Generally, a selection effect is found in studies of health complaints among older employees, often ascribed to the high number of health related drop outs in this age group. ${ }^{413}$ Health related selection already affects the composition of an elderly study population at the start of a follow up study. This phenomenon might be a plausible explanation for the flattening or decreasing prevalences of musculoskeletal complaints at the first survey in the oldest age group within heavy physical work. Also, the employees in our study were selected because of participation in a survey twice, with a restricted time interval in between. This criterion may also have resulted in a health 
related selection of subjects, excluding those employees who were not able to participate a second time-for example, due to a health related drop out.

Unfortunately, within the original survey data set, the reasons for not participating a second time were not registered. Potential reasons could be change in job, disablement, retirement, second survey not within our study interval 1982-93, company stopped participating, or changed from occupational health service, etc. Due to the large variety and vagueries of these potential reasons, an appropriate analysis on the drop outs within this study population was not possible. For this purpose an additional study has been performed on a specific selected population from the data set
(De Zwart et $a l^{14}$ ). It was found that of all employees who participated in one survey, around $70 \%$ also participated in the next after four years, while still working within the same type of job and company. Back complaints as well as high age at the first survey were both found to be associated with no participation (drop out) at the second survey. Within the four year follow up study of Tuomi et $a l^{15}$ among 2797 employees aged $44-58$ years, $65 \%$ of them still had the same occupation at the end of the study. Of all drop outs, almost $32 \%$ became disabled, $26 \%$ did not respond, $17 \%$ changed occupation, $17 \%$ retired, and $6 \%$ died. Changing occupation, becoming too disabled to work, and mortality occurred most

Table 3 Prevalences (PRs) of musculoskeletal complaints at T1 and T2, and changes in prevalences between T1 and T2 (T2-T1) for male employees, stratified for age group and types of work demands (age group refers to age at T1)

\begin{tabular}{|c|c|c|c|c|c|c|c|c|c|c|c|c|}
\hline \multirow[b]{4}{*}{ Site of complaints } & \multicolumn{12}{|c|}{ Age group (y) } \\
\hline & \multicolumn{3}{|c|}{$20-9$} & \multicolumn{3}{|c|}{$30-9$} & \multicolumn{3}{|c|}{$40-9$} & \multicolumn{3}{|c|}{$50-9$} \\
\hline & \multicolumn{3}{|c|}{$P R(\%)$} & \multicolumn{3}{|c|}{$P R(\%)$} & \multicolumn{3}{|c|}{$P R(\%)$} & \multicolumn{3}{|c|}{$P R(\%)$} \\
\hline & $T 1$ & $T 2$ & $T 2-T 1$ & $T 1$ & $T 2$ & $T 2-T 1$ & $T 1$ & $T 2$ & $T 2-T 1$ & $T 1$ & $T 2$ & $T 2-T$ \\
\hline \multicolumn{13}{|l|}{ Back: } \\
\hline Mental & 10 & 16 & 5 & 16 & 19 & 3 & 21 & 23 & 2 & 22 & 26 & 4 \\
\hline Heavy physical & 19 & 25 & 6 & 27 & 34 & $6^{\star}$ & 31 & 39 & $8^{\star \star \star}$ & 28 & 31 & 3 \\
\hline \multicolumn{13}{|l|}{ Middle of the back: } \\
\hline Mental & 3 & 5 & 2 & 6 & 8 & 2 & 8 & 9 & 1 & 9 & 10 & 1 \\
\hline Heavy physical & 10 & 11 & 1 & 14 & 16 & 2 & 16 & 20 & $4^{\star}$ & 14 & 16 & 1 \\
\hline Low back: & & & & & & & & & & & & \\
\hline Mental & 6 & 9 & 3 & 10 & 13 & 3 & 14 & 15 & 1 & 14 & 16 & 2 \\
\hline Heavy physical & 9 & 14 & $6^{\star}$ & 14 & 19 & $5^{\star}$ & 16 & 21 & $5^{\star \star}$ & 15 & 18 & 3 \\
\hline Radiating: & & & & & & & & & & & & \\
\hline Mental & 2 & 5 & 2 & 6 & 6 & 0 & 7 & 7 & 0 & 8 & 9 & 1 \\
\hline Heavy physical & 4 & 8 & 4 & 9 & 13 & $4^{\star \star \star}$ & 11 & 15 & $5^{\star \star \star}$ & 10 & 12 & 2 \\
\hline Neck: & & & & & & & & & & & & \\
\hline Mental & 6 & 9 & 3 & 8 & 11 & 3 & 10 & 13 & 3 & 16 & 18 & 2 \\
\hline Heavy physical & 7 & 12 & $6^{\star}$ & 10 & 14 & 4 & 13 & 21 & $7 \star \star$ & 13 & 18 & $5^{\star}$ \\
\hline Upper limbs: & & & & & & & & & & & & \\
\hline Mental & 4 & 6 & 2 & 10 & 14 & 4 & 15 & 20 & 5 & 21 & 25 & 4 \\
\hline Heavy physical & 13 & 17 & 4 & 20 & 27 & $7^{\star}$ & 26 & 33 & 7 & 27 & 32 & 5 \\
\hline Shoulder: & & & & & & & & & & 21 & J2 & S \\
\hline Mental & 2 & 4 & 2 & 7 & 8 & 2 & 9 & 13 & 4 & 13 & 17 & 4 \\
\hline Heavy physical & 8 & 12 & $5^{\star}$ & 13 & 18 & $5 \star \star \star$ & 17 & 24 & $7 \star \star$ & 18 & 24 & 5 \\
\hline Upper arm: & & & & & & & & & & & & \\
\hline Mental & 1 & 2 & 1 & 3 & 4 & 0 & 6 & 8 & 2 & 10 & 11 & 1 \\
\hline Heavy physical & 3 & 5 & 1 & 7 & 9 & $2^{\star \star}$ & 11 & 15 & 4 & 11 & 16 & $5^{\star}$ \\
\hline Elbow: & & & & & & & & & & & & \\
\hline Mental & 1 & 1 & 0 & 1 & 3 & 1 & 4 & 5 & 1 & 6 & 5 & -1 \\
\hline Heavy physical & 2 & 2 & 0 & 4 & 8 & $3^{\star \star}$ & 8 & 11 & $3^{\star}$ & 8 & 10 & 2 \\
\hline Forearm: & & & & & & & & & & & & \\
\hline Mental & 0 & 1 & 1 & 1 & 2 & 1 & 2 & 3 & 1 & 2 & 3 & 1 \\
\hline Heavy physical & 1 & 2 & 1 & 3 & 4 & 1 & 5 & 6 & 1 & 5 & 6 & 1 \\
\hline Wrist: & & & & & & & & & & & & \\
\hline Mental & 1 & 1 & 0 & 1 & 1 & 0 & 2 & 2 & 1 & 3 & 4 & 1 \\
\hline Heavy physical & 4 & 3 & 0 & 4 & 5 & 1 & 4 & 6 & $2^{\star}$ & 5 & 6 & 1 \\
\hline Hand or fingers: & & & & & & & & & & & & \\
\hline Mental & 1 & 2 & 1 & 2 & 3 & 1 & 3 & 5 & 1 & 6 & 7 & 2 \\
\hline Heavy physical & 4 & 4 & 0 & 5 & 7 & 2 & 8 & 10 & 2 & 8 & 11 & 2 \\
\hline Lower limbs: & & & & & & & & & & & & \\
\hline Mental & 9 & 9 & 0 & 11 & 14 & 3 & 17 & 17 & 0 & 20 & 24 & 5 \\
\hline Heavy physical & 17 & 20 & $3^{\star}$ & 22 & 27 & 4 & 26 & 32 & $6^{\star \star \star}$ & 28 & 32 & 4 \\
\hline Hip: & & & & & & & & & & & & \\
\hline Mental & 1 & 1 & 0 & 2 & 3 & 1 & 5 & 6 & 0 & 6 & 10 & 4 \\
\hline Heavy physical & 2 & 3 & 1 & 5 & 7 & $2^{\star}$ & 9 & 13 & $4^{\star \star}$ & 12 & 13 & 1 \\
\hline Upper leg: & & & & & & & & & & & & \\
\hline Mental physical & 1 & 1 & 0 & 2 & 3 & 1 & 5 & 5 & 0 & 6 & 7 & 1 \\
\hline Heavy physical & 2 & 4 & $1^{\star}$ & 5 & 6 & 1 & 7 & 11 & $4^{\star \star \star}$ & 10 & 10 & 0 \\
\hline Knee: & & & & & & & & & & & & \\
\hline Mental & 5 & 5 & 0 & 6 & 7 & 1 & 7 & 7 & 0 & 8 & 10 & 2 \\
\hline Heavy physical & 9 & 12 & $3^{\star}$ & 12 & 15 & $3^{\star}$ & 13 & 16 & $3 \star \star \star$ & 14 & 17 & 3 \\
\hline Lower leg: & & & & & & & & & & & & \\
\hline Mental & 1 & 1 & 0 & 2 & 3 & 1 & 5 & 6 & 1 & 8 & 8 & 1 \\
\hline Heavy physical & 2 & 4 & $2 \star \star$ & 6 & 7 & 1 & 8 & 10 & 2 & 8 & 9 & 2 \\
\hline Ankle: & & & & & & & & & & & & \\
\hline Mental & 2 & 2 & 0 & 2 & 2 & 0 & 3 & 3 & -1 & 3 & 3 & 1 \\
\hline Heavy physical & 3 & 4 & 1 & 4 & 5 & 1 & 5 & 6 & $2^{\star \star}$ & 4 & 5 & 1 \\
\hline Foot or toes: & & & & & & & & & & & & \\
\hline Mental & 2 & 1 & -1 & 1 & 2 & 1 & 3 & 4 & 0 & 3 & 5 & 2 \\
\hline Heavy physical & 4 & 4 & 0 & 5 & 6 & 1 & 5 & 7 & $2^{\star}$ & 6 & 7 & 2 \\
\hline
\end{tabular}


Table 4 Distribution of male employees (\%) on the basis of their condition at T1 and T2 for musculoskeletal complaints

\begin{tabular}{|c|c|c|c|c|c|}
\hline Age group & $\begin{array}{l}T 1 T 2 \\
(++)\end{array}$ & $\begin{array}{l}T 1 T 2 \\
(-+)\end{array}$ & $\begin{array}{l}T 1 T 2 \\
(+-)\end{array}$ & $\begin{array}{l}T 1 T 2 \\
(-)\end{array}$ & $\begin{array}{l}P R(\%) \text { at } T 2 \text { in } \\
\text { cohort free of } \\
\text { complaints at } \\
T 1 t\end{array}$ \\
\hline \multicolumn{6}{|l|}{ Back: } \\
\hline \multicolumn{6}{|l|}{ Mental: } \\
\hline 20-9 & 6 & 10 & 4 & 80 & 11 \\
\hline $30-9$ & 9 & 10 & 7 & 74 & 12 \\
\hline $40-9$ & 14 & 9 & 7 & 69 & 12 \\
\hline $50-9$ & 15 & 11 & 7 & 68 & 13 \\
\hline \multicolumn{6}{|c|}{ Heavy physical: } \\
\hline $20-9$ & $11^{\star \star \star}$ & $14^{\star \star}$ & $8^{\star \star \star}$ & $67^{\star \star \star \star}$ & $18^{\star \star \star}$ \\
\hline $30-9$ & $19^{\star \star \star}$ & $15^{\star \star \star}$ & $9^{\star}$ & $58^{\star \star \star}$ & $20^{\star \star \star}$ \\
\hline $40-9$ & $23^{\star \star \star \star}$ & $16^{\star \star \star}$ & 8 & $53^{\star \star \star \star}$ & $23^{\star \star \star \star}$ \\
\hline $50-9$ & $20 \star$ & 11 & 8 & $61^{\star \star}$ & 15 \\
\hline \multicolumn{6}{|l|}{ Neck: } \\
\hline \multicolumn{6}{|l|}{ Mental: } \\
\hline $20-9$ & 3 & 6 & 3 & 88 & 7 \\
\hline $30-9$ & 4 & 7 & 4 & 85 & 7 \\
\hline $40-9$ & 5 & 8 & 4 & 83 & 9 \\
\hline $50-9$ & 10 & 8 & 6 & 76 & 9 \\
\hline \multicolumn{6}{|c|}{ Heavy physical: } \\
\hline $20-9$ & 3 & $9^{\star}$ & 3 & $84^{\star}$ & $10^{\star}$ \\
\hline $30-9$ & $6^{\star \star}$ & 8 & 4 & $81^{\star \star}$ & $9 \star$ \\
\hline $40-9$ & $9^{\star \star \star}$ & $11^{\star \star \star}$ & 4 & $75^{\star \star \star}$ & $13^{\star \star \star}$ \\
\hline $50-9$ & 8 & 10 & 5 & 77 & 11 \\
\hline \multicolumn{6}{|c|}{ Upper limbs: } \\
\hline \multicolumn{6}{|c|}{ Mental: } \\
\hline $20-9$ & 1 & 5 & 3 & 92 & 5 \\
\hline $30-9$ & 5 & 9 & 5 & 81 & 10 \\
\hline $40-9$ & 9 & 12 & 7 & 73 & 14 \\
\hline $50-9$ & 12 & 13 & 8 & 66 & 16 \\
\hline \multicolumn{6}{|c|}{ Heavy physical: } \\
\hline $20-9$ & $7 \star \star \star \star$ & $10^{\star \star \star}$ & $6^{\star \star \star}$ & $77^{\star \star \star \star}$ & $12^{\star \star \star}$ \\
\hline $30-9$ & $12^{\star \star \star}$ & $15^{\star \star \star}$ & 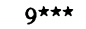 & $65^{\star \star \star}$ & $19^{\star \star \star}$ \\
\hline $40-9$ & $17^{\star \star \star}$ & $16^{\star \star}$ & 8 & $59^{\star \star \star}$ & $21^{\star \star \star}$ \\
\hline $50-9$ & $18^{\star \star}$ & 15 & 10 & $58^{\star \star \star}$ & 20 \\
\hline \multicolumn{6}{|c|}{ Lower limbs: } \\
\hline \multicolumn{6}{|c|}{ Mental: } \\
\hline 20-9 & 3 & 7 & 6 & 85 & 7 \\
\hline $30-9$ & 5 & 8 & 6 & 81 & 9 \\
\hline $40-9$ & 8 & 9 & 9 & 75 & 11 \\
\hline $50-9$ & 12 & 12 & 8 & 68 & 15 \\
\hline \multicolumn{6}{|c|}{ Heavy physical: } \\
\hline $20-9$ & $8^{\star \star \star}$ & $12^{\star \star \star}$ & $9^{\star}$ & $71^{\star \star \star}$ & $14^{\star \star \star}$ \\
\hline $30-9$ & $13^{\star \star \star}$ & $14^{\star \star \star}$ & $10^{\star \star \star}$ & $64^{\star \star \star}$ & $18^{\star \star \star}$ \\
\hline $40-9$ & $16^{\star \star \star}$ & $16^{\star \star \star}$ & 9 & $59 \star \star \star$ & $21^{\star \star \star \star}$ \\
\hline $50-9$ & $19^{\star \star \star}$ & 14 & 10 & $58^{\star \star \star}$ & 19 \\
\hline
\end{tabular}

${ }^{\star} \mathrm{P}<0.05 ;{ }^{\star \star} \mathrm{P}<0.01 ;{ }^{\star \star \star} \mathrm{P}<0.001, \chi^{2}$ comparing frequency or prevalences in heavy physical work $v$ this in mental work withing the same age group.

$\nmid$ Rough approximation of the cumulative incidence rate over the four year interval.

$+=$ complaint; $-=$ no complaint.

Age group refers to age at $\mathrm{T} 1$. conditions. $^{3}$ Demanding work factors may exacerbate the subjective complaints of a specific musculoskeletal disorder. For example, a construction worker with a knee injury will probably more readily complain about this injury than a person in a sedentary job experiencing the same injury. Within our study this interaction effect may have resulted in some reporting bias.

AGE GROUP DIFFERENCES

In several longitudinal studies focusing on employees in physically demanding jobs, increasing prevalences of musculoskeletal complaints over several years have been reported. ${ }^{61718}$ None of these studies, however, stratified for age.

Among those employees aged 40-9, exposure to heavy physical work increased prevalences over the follow up interval of a wide range of musculoskeletal complaints, causing the highest prevalences at the second survey of new complaints of the back, neck, and the upper and lower limbs within the cohort free of complaints at the first survey. Perhaps in employees in this age group the many years of exposure to harmful physical work demands combined with the changed balance between physical workload and physical work capacity might result in a high risk of work related musculoskeletal disorders. Also, it is probable that employees of this particular age were exposed to extreme physical work demands at the beginning of their careers. ${ }^{19}$ In the category of heavy physically demanding work, employees were exposed to tasks such as lifting heavy objects, manually handling heavy tools, stooping, etc. Positive associations between these work related tasks and musculoskeletal complaints have been reported earlier. ${ }^{20}$

Also, in the age group 20-9, exposure to physical work demands was found to increase the prevalences of several musculoskeletal complaints. Among these younger employees a relatively large increase of back complaints was found. Comparatively high frequencies of first lumbar complaints among younger employees have also been reported by others. ${ }^{121-23}$ So, although for younger employees the cumulative effects of the number of years of exposure to heavy physical work demands are relatively low and physical work capacity is normally at its highest, ${ }^{10}$ exposure to heavy physical work demands is already a risk factor for the onset of musculoskeletal complaints. It is possible that a lack of experience in, for example, the skilled manipulation of heavy weights, contributes to the susceptibility of younger employees to musculoskeletal disorders. ${ }^{124}$

Over four years the oldest employees in heavy physically demanding occupations, as opposed to those with mental work, had a significantly greater increase in prevalence of complaints of only the neck and upper arm. For all complaints investigated, the prevalence in the oldest employees at the second survey in the cohort free of complaints at the first survey was found to be lower than that within the group for employees aged 40-9 years. The most dramatic drop between these prevalences that reported health complaints of employees partly depend on the interaction between existing health problems and current working 
from the 40-9 year old age group and the oldest age group was for back complaints. These findings can be attributed to the health related selection effect already mentioned, which led to an underestimation of occupational health risks in cross sectional and longitudinal epidemiological studies. ${ }^{52}$ Especially within the oldest age groups in heavy physically demanding work, the drop out rate as a result of disablement caused by musculoskeletal complaints is high. ${ }^{26}$ Tuomi et $a l,{ }^{16}$ reported a sharp increase in the incidence of work disability around the age of 55 years in their study. Referring to the national disablement statistics of 1994 in The Netherlands this rapid rise was already becoming obvious around the age of 50 years. ${ }^{27}$ Thus, the elderly subjects in our study who managed to participate twice in a survey, while still working in a heavy physically demanding job and free of complaints at the first survey, may be regarded as a relatively healthy group of survivors. The presence of a low cumulative incidence of musculoskeletal complaints in this group may, therefore, not be surprising. According to this line of reasoning, our findings suggest that back complaints were a predominant cause of health related drop out of older employees. This suggestion is supported by disorder specific disablement figures from The Netherlands, covering several years of our study period. ${ }^{28}$

\section{Conclusions}

The data of this study show that especially among employees aged 40-9 exposure to heavy physical demands in the work situation is associated with the development of a wide range of musculoskeletal complaints. However, also in the younger age groups several effects of exposure to heavy physical work demands were found. Furthermore, it seems that a health related selection during the working life results in a relatively healthy group of employees within the oldest age group of heavy physically demanding occupations. These findings emphasise that policy measures directed to the survivor group of elderly employees above $\mathbf{5 0}$ years of age only, does not seem to be adequate and effective in the long term. Preventive measures should be taken at all stages of a working life, taking into account the changing balance between the physical workload and the individual physical work capacity with advancing age.

We thank the staff of the Occupational Health Service "Oost-Gelderland" in Doetinchem for providing their data on periodical occupational health surveys and Dr Allard J van de Beek and Herman JA Sallé for their useful suggestions with regard to the manuscript.

\section{Appendix}

The epidemiological effect measure $(Y)$, representing the change in prevalence (PR) between the first (T1) and second (T2) surveys in the exposed group (e) minus the change in the control group (r), as used within this study, can be described by:

$$
Y=\left(P R_{T 2}-P R_{T}\right)_{e}-\left(P R_{T 2}-P R_{T}\right)_{r}
$$

Table A Potential combinations of conditions of musculoskeletal complaints at T1 and $T$

\begin{tabular}{llllll}
\hline Study group & $(--)$ & $(-+)$ & $(+-)$ & $(++)$ & Total \\
\hline $\begin{array}{c}\text { Exposed } \\
\text { group (e) }\end{array}$ & $\mathrm{P}_{--\mathrm{e}}$ & $\mathrm{P}_{-+\mathrm{e}}$ & $\mathrm{P}_{+-\mathrm{e}}$ & $\mathrm{P}_{++\mathrm{e}}$ & $\mathrm{N}_{\mathrm{e}}$ \\
$\begin{array}{c}\text { Reference } \\
\text { group (r) }\end{array}$ & $\mathrm{P}_{--\mathrm{r}}$ & $\mathrm{P}_{-+\mathrm{r}}$ & $\mathrm{P}_{+-\mathrm{r}}$ & $\mathrm{P}_{++\mathrm{r}}$ & $\mathrm{N}_{\mathrm{r}}$
\end{tabular}

$P$ stands for proportion of employees of total study group (exposed or reference).

--Free of complaints, no complaints at both surveys; -+new cases, only complaints at T2; +-recovered cases, only complaints at $\mathrm{T} 1 ;++$ chronic cases, complaints at both surveys.

With the notation presented in table A, the effect parameter $Y$ can also be expressed as:

$$
Y=\left(P_{-+\mathrm{e}}-P_{+-\mathrm{e}}\right)-\left(P_{-+\mathrm{r}}-P_{+-r}\right)
$$

The asymptotically normal test statistic based on $\mathrm{Y}$ is given by the following equation derived from the general equation used for statistical testing based on a normal distribution as described by Rothman ${ }^{29}$ :

$$
z=\frac{Y}{\sqrt{\operatorname{var}(Y)}}
$$

The variance of $Y(\operatorname{var}(Y))$ within this test statistic is given by the following formula (with $i$ indicating the exposed group or control group):

$$
\begin{aligned}
& \operatorname{var}(Y)=\sum_{i} \operatorname{var}\left(P_{-+\mathrm{i}}-P_{+-\mathrm{i}}\right)= \\
& \sum_{i} \frac{1}{N_{i}}\left(P_{-+\mathrm{i}}+P_{+-\mathrm{i}}-\left(P_{-+\mathrm{i}}-P_{+-\mathrm{i}}\right)^{2}\right)
\end{aligned}
$$

1 Luttman A, Jäger M, Laurig W, Schlegel KF. Orthopaedic diseases among transport workers. Int Arch Occup Environ Health 1988;61:197-205.

2 Törner M, Blide G, Eriksson H, Kadefors R, Karlsson R, Torner M, Blide G, Eriksson $\mathrm{H}$, Kadefors $\mathrm{R}$, Karlsson $\mathrm{R}$,
Petersen I. Musculo-skeletal symptoms as related to working conditions among Swedish professional fishermen. ing conditions among Swedish pro

3 Broersen JPJ, De Zwart BCH, Van Dijk FJH, Meijman TF Van Veldhoven $M$. Health complaints and working conditions experienced in relation to work and age. Occup Environ Med 1996;53:51-7.

4 De Zwart BCH, Broersen JPJ, Frings-Dresen MHW, Van Dijk FJH. Musculoskeletal complaints in the Netherlands in relation to age, gender, and physically demanding work. Int Arch Occup Environ Health (in press).

5 Hernberg S. Work related diseases-some problems in study design. Scand $¥$ Work Environ Health 1984;10:367-72.

6 Tuomi K, Ilmarinen J, Eskelinen L, Järvinen E, Toikkanen J Klockars M. Prevalence and incidence rates of diseases and work ability in different work categories of municipal occupations. Scand $\mathcal{F}$ Work Environ Health 1991;17(suppl 1):6774.

7 Buckwalter JA. Aging and degeneration of the human intervertebral disc. Spine 1995;20:1307-14.

8 Undeutsch K, Gärtner KH, Luopajärvi, Küpper R, Karvonen MJ, Löwenthal I, Rutenfranz J. Back complaints and findings in transport workers performing physically heavy work. Scand $\mathcal{F}$ Work Environ Health 1982;8 (suppl 1):92-6.

9 Ilmarinen J, Tuomi K, Eskelinen L, Nygård C-H, Huuhtanen $P$, Klockars $M$. Summary and recommendations of project involving cross-sectional and follow-up studies on project involving cross-sectional and follow-up studies on the aging worker in Finnish municipal occupations (1981-

5). Scand $\mathcal{F}$ Work Environ Health 1991;17(suppl 1):135-41. Physical workload and the ageing worker: a review of the Physical workload and the ageing worker: a review of the

11 Van Dijk FJH, Weel ANH, Broersen JPJ. Identification of work-related diseases by periodic occupational health surveys-experiences in the Netherlands. In: Mehlman MA, Upton A, eds. Advances in modern environmental toxicology. Princeton: Princeton Sci Publ, 1994;23:75-91.

12 De Zwart BCH, Broersen JPJ, Van der Beek AJ, FringsDresen MHW, Van Dijk FJH. Occupational classification according to work demands: an evaluation study. Int $\mathcal{f}$ Occup Med Environ Health (in press)

13 Hildebrandt VH. Back pain in the working population: prevalence rates in Dutch trades and professions. Ergonom ics 1995;38:1283-98.

14 De Zwart BCH, Broersen JPJ, Van der Beek AJ, FringsDresen MHW, Van Dijk FJH. Selection related to musculoskeletal complaints among employees. Occup Environ Med 1997;54:800-6. 
15 Tuomi K, Toikkanen J, Eskelinen L, Backman A-L, Ilmarinen J, Järvinen E, Klockars M. Mortality, disability and changes in occupation among aging municipa employees. Scand $\mathcal{f}$ Work Environ Health 1991;17(supp 1):58-66.

16 Mackenbach JP. Socio-economic health differences in the Netherlands: a review of recent empirical findings. Soc $S c i$ Med 1992;34:213-26.

17 Berg M, Sandén $\AA$, Torell G, Järvholm B. Persistence of musculoskeletal symptoms: a longitudinal study. Ergonomics $1988 ; 31: 1281-5$.

18 Viikari-Juntura E, Riihimäki $H$, Tola $S$, Videman $T$, Mutanen P. Neck trouble in machine operating, dynamic physical work and sedentary work: a prospective study on occupational and individual risk factors. $\mathcal{F}$ Clin Epidemiol 1994;47:1411-22.

19 Gibbons LE, Battié MC, Videman T. Changes in occupational physical loading during the lifetimes of Finnish men. Scand $\mathcal{F}$ Work Environ Health 1995;21:208-14.

20 Riihimäki H. Back and limb disorders. In: McDonald JC ed. Epidemiology of work related diseases. London: BMJ, 1995:207-38.

21 Sairanen E, Brüshaber L, Kaskinen M. Felling work, low-back pain and osteoarthritis. Scand $f$ Work Environ Health 1981;7:18-30.
22 Kelsey JL, Golden AL, Mundt DJ. Low back pain/prolapsed umbar intervertebral disc. Rheum Dis Clin North Am 1990 16:699-716.

23 Garg A, Moore JS. Epidemiology of low-back pain in industry. Occup Med 1992;7:593-608.

24 Authier M, Lortie M, Gagnon M. Manual handling techniques: comparing novice and experts. International fournal of Industrial Ergonomics 1996;17:419-29.

25 Ostlin P. The health-related selection effect on occupational morbidity rates. Scand $\mathcal{F}$ Soc Med 1989;17:265-70.

26 Arndt V, Rothenbacher D, Brenner H, Fraisse E, Zschenderlein B, Daniel U, et al. Older workers in the construction industry: results of a routine health examination struction industry: results of a routine health examination 91 .

27 Gemeenschappelijke Medische Dienst (GMD). Statistisch jaarverslag 1994 (Statistical annual 1994). Amsterdam: GMD, 1995

28 Verbeek JHAM. Arbeidsongeschiktheid op grond van aandoeningen van het bewegingsapparaat: een beschrijvin (Disability because of disorders of the musculoskeleta system: a descriptive study). Tijdschrift voor Sociale Gezondheidszorg 1988;66:22-6.

29 Rothman KJ. Modern epidemiology. Boston: Little Brown, 1986.

\section{Correspondence and editorials}

Occupational and Environmental Medicine welcomes correspondence relating to any of the material appearing in the journal. Results from preliminary or small scale studies may also be published in the correspondence column if this seems appropriate. Letters should be not more than 500 words in length and contain a minimum of references. Tables and figures should be kept to an absolute minimum.
Letters are accepted on the understanding that they be subject to editorial revision and shortening.

The journal also publishes editorials which are normally specially commissioned. The Editor welcomes suggestions regarding suitable topics; those wishing to submit an editorial, however, should do so only after discussion with the Editor. 